\title{
Problems and Countermeasures of Public Transport Management in Zhanjiang City of China
}

\author{
Sun GaoAng ${ }^{1, *}$ \\ ${ }^{1}$ Department of Public Administration, School of Management, Guangdong Ocean University, Mazhang District, \\ Zhanjiang, Guangdong, China \\ asungaoang@hotmail.com
}

\begin{abstract}
With the continuous growth of the national economy, the demand for public transportation has increased and the requirements for public transportation's economy, comfort and portability have deepened. The construction of urban public transportation should be strongly pushed forward to attract more citizens to travel by it, which will alleviate urban traffic congestion. As the increasing urbanization of Zhanjiang City, the number of motor vehicles in urban areas has shown a high-speed development, which has caused huge challenges in traffic management. Therefore, the essay uses a variety of research methods in the process, learning and drawing on the experience of traffic management in large and medium-sized cities at home and abroad, and exploring the main causes of urban congestion. In terms of the development of public transportation in Zhanjiang City, the problems existing in the current stage of Zhanjiang City are summarized and implementing measures are proposed, including a sound management system, guarantee of the investment in the construction of the transportation network structure and strengthening the infrastructure of the station.
\end{abstract}

Keywords: Public transportation; Zhanjiang; City planning

\section{中国湛江市区公共交通管理存在的问题与对策}

\author{
孙高昂 ${ }^{1, a}$
}

1 公共管理系, 管理学院, 广东海洋大学, 麻章区, 湛江市, 广东省, 中国

${ }^{a}$ sungaoang@hotmail.com

\begin{abstract}
摘要
随着国民经济不断增长，民众对于公共交通出行的需求也随之增长，民众对于公共交通安全性、经济 性、舒适性和便捷性等要求日益加深。大力推进城市公共交通建设, 能够吸引更多民众以公共交通的 方式出行, 进而有助于缓解城市交通堵塞。随着湛江市区城市化推进日益明显, 城市机动车保有量呈 现出高速发展状态，造成交通管理陷入巨大挑战。因此本论文在开展研究过程中综合运用多种研究方 法, 学习和借鉴国内外大中城市交通管理经验，探索造成城市拥堵的主要原因，根据湛江市区公共交 通发展自身情况，总结现阶段湛江市区公共交通所存在的问题，并提出具有可实施性的改进对策，包 括健全管理体制、保障交通线网结构建设资金投入和加强场站基建设施。
\end{abstract}

关键词: 公共交通; 湛江; 城市规划

\section{1. 导论}

\section{1 研究背景}

2012 年我国出台与 “城市优先发展公共交通” 相关 的管理性文件, 指出需要转化城市交通发展方式, 强调
城市公共交通公益属性，在未来时间段内投入大量资源， 致力于提高城市公共交通水平, 并就城市规划、基建设 施完善、技术平台、管理条例等方式加以明确。我国城 市交通管理需要从全局角度出发, 采用多种策略, 积极 改善交通供需关系, 缓解交通拥堵。湛江市政府近年来 多次发布相关文件, 在以人为本的基础上推动公共交通 建设, 致力于优化交通网络线路、提升换乘效率、改善 公共交通服务等，切实提升公共交通在城市建设中的地 
位，为民众带来具有安全性、便捷性、舒适性和环保性 的公共交通系统, 以满足民众日常出行需要。

\section{2 研究目的}

公共交通建设市城市基建体系中的重要组成部分, 在湛江市区城市建设中具有重要地位, 随着湛江市区城 市规模扩大和城区人口增多, 当前的公共交通体系已难 以满足城市发展需要, 交通拥堵、出行困难等问题受到 当地民众关注，同时也对湛江市区民众正常生产、学习 和生活带来消极影响。就现实意义而言, 本论文首先总 结湛江市区公共交通管理过程中所暴露的问题, 并对这 些问题作出成因分析, 以此为基础提出改善湛江市区公 共交通拥堵的对策，增强公共交通管理能力，保障民众 出行需求, 进而合理配置道路资源, 减轻城市管理成本 压力, 促进城市健康有序发展, 由此可见, 本论文研究 内容具有较强的现实意义。

\section{3 文献综述}

李红宇（2015）在其文章中指出我国公共交通道路 大多数通道为双向四车道, 且具有路面宽度窄、道路坡 度大、道路标准并不满足国家要求等特征, 同时随着经 济发展, 机动车保有量保持着每年 $15 \%$ 左右的提升速度。 由于主干道道路网络并不完善, 缺少必要的对接道路, 导致道路通达性较差, 主干道承受的交通压力较高, 加 之车流量大、车流高度集中, 致使干道交通在高峰时出 现拥堵, 并根据这些现象认为完善交通网络, 扩大主干 道通行力是解决公共交通道路问题的主要方式。

宋旗 (2017) 以常德市为研究对象, 指出不少商圈 环道为单向交通, 导致车辆在行驶过程中的绕行距离较 长, 不少过境车辆也在环道中驾驶, 进一步增多交通流 量, 造成商圈周边往往出现排队进停车场的情况, 导致 交通堵塞, 并提出改善建议, 同时认为政府部门需要充 分发挥主观能动性, 制定科学管理对策, 推进公路视频 监控系统建设, 通过动态化管理, 全方位开展取证、布 控、拦截、处罚工作, 能够有效改善公共交通管理质量。

呼延梦石（2018）在其硕士毕业论文中，以徐州市 为研究对象, 指出城市公共交通管理近年来成为我国社 会管理中的重点, 并从多个角度对徐州市城市公共交通 管理中存在的问题进行原因分析, 就当地城市交通管理 过程中的规章制度、运行机制作出探讨, 形成具有可实 施性的交通管理对策。

郭飞（2015）认为公共交通管理陷入困境与当地警 务勤务管理能力不足存在直接性联系, 并指出在公共交 通管理中, 应遵循警力资源随交流流量变化而变化, 警 力随警情分布, 强化勤务指挥意识, 扩大勤务管控水准、 加强勤务联动, 通过改革创新, 优化勤务管理内部结构。

张圣林等 (2018) 经过长期研究, 认为我国可以学 习和借鉴新加坡法律中的 “陆权优先” 规定, 对车流和 人流的通行顺序进行规定, 对闯红灯所引发的交通事故
和交通拥堵进行责任区分, 强化惩罚力度, 依法进行重 大事故责任处理, 切实打击交通违法违规现象，提升公 共交通管理的严肃性和权威性。

\section{4 公共交通的理论基础}

\subsection{1 城市规划}

城市规划是指对城市未来发展建设进行规范和设 计, 对城市进行整体布局, 综合安排落实城市工程建设 的全局部署，是一段时间内城市宏观发展的蓝图，同时 也是城市管理工作的重要组成。城市规划是城市建设、 城市运行的基础。城市规划应基于可持续发展眼光, 采 用合理论证、科学决策的方式, 对城市整体经济建设、 产业结构、基建设施等作出全面规划, 通常也包括城市 片区结构管理规划等, 对城市建设具有重要意义, 是城 市公共管理的基础所在, 同时也是梳理复杂城市管理的 基础。城市建设综合性、复杂性和时代性特征, 决定城 市规划需要随着时间推移、社会发展进行不断修整和改 进, 是需要持续决策的重要过程。

\subsection{2 基础设施}

基础设施可以分为交通站点、机场、桥梁、港口、 水电气等供应设施、通信设施以及其他为社会民众服务、 科教文卫事业服务的固定资产, 是民众生产生活的基础 所在, 是城市建设发展的保障。基础设施不光是物质层 面生产推进的基础条件, 同时也是社会生产力提升、劳 动力资源发挥作用的重要支撑。基础设施是现代社会建 设、文明进步的基础，完善的基础设施能够为城市发展 带来能量, 激发社会各界城市建设的积极性, 落后的基 础设施为约束城市发展和经济建设。目前我国城市基础 设施建设能力不断提高, 新理念、新技术、新设备广泛 应用, 基础设施整体承载力、建设效率获得明显提高, 为社会民众生产生活环境改善提供正向作用。

\section{4.3 公共交通}

公共交通通常是指向民众全面开放、带来一定运输 服务能力的交通方式, 大多数情况下公共交通具有商业 性, 民众需要通过付费使用的方式进行使用, 也有一定 的免费情况。公共交通存在于社会民众身边, 为民众带 来出行服务, 通常包括道路、桥梁、交通工具、站点设 施设备等。从广义角度而言, 公共交通运输方式可以包 括民航运运输、铁路运输、公路运输、水运运输, 这些 运输方式为现代社会发展创造良好环境; 狭义公共交通 运输主要包括在城市建设过程中, 定点定线运营的公共 汽车、轨道式交通、渡轮等常见交通方式, 根据运输内 容不同, 可以分为人员公共运输和货物公共运输。社会 各界常讲的 “公共交通” 是指人员公共运输, 因此在部 
分情况下，公共交通和公共运输存在概念相通性。

\section{2. 湛江市区公共交通管理现状}

湛江市区包括赤坎区、霞山区、坡头区和麻章区， 湛江市第一条公共交通线路开设于 1959 年，截至 2018 年底, 目前共有公交线路 83 条。目前湛江公交车辆数 量共有 788 辆, 包括清洁能源公交车 170 辆, 新能源公 交车 618 辆 (如表 1 所示)。自 2018 年起湛江公交车目 前已支持支付宝乘车码支付、现金支付、公交 IC 卡刷 卡支付，暂时不支持微信支付。湛江市交通局负责进行 公共交通管理统筹, 2018 年湛江市公路通车公里数为 2.21 万公里, 汽车保有量为 57.44 万辆, 同比增加 $22.9 \%$ 。 湛江机场位于湛江市区西北部, 距离市中心约 5 公里, 为国家 $4 \mathrm{D}$ 级机场, 按 $4 \mathrm{C}$ 标准保障, 截至 2018 年底, 可直接与 30 个城市进行直接同行, 其中国内城市 27 个, 国际城市 3 个, 即中国香港、曼谷和金边。2018 年湛江 市动工建设飞行等级为 $4 \mathrm{E}$ 级的湛江国际机场, 预计 2020 年建成。湛江火车站位于霞山区解放西路, 始建于 1955 年, 属南宁铁路局管辖的一等站。湛江站位于广东、 海南、广西三省交界处, 与湛江港距离较近, 是我国西 南地区客货运交通枢纽。

表 1 湛江市公交车数量和种类分布

\begin{tabular}{|c|c|c|c|c|}
\hline 种类 & $\begin{array}{c}\text { 清洁能 } \\
\text { 源公交 } \\
\text { 新能源公交车 }\end{array}$ & \multirow{2}{*}{ 纯电动 } & $\begin{array}{c}\text { 气电混 } \\
\text { 总计 }\end{array}$ & \\
\hline 数量 & 170 & 340 & 278 & 788 \\
\hline
\end{tabular}

目前湛江市区公交班线虽然能够为民众提供一定 便利, 仍由于管理、服务等多方面缘由, 呈现出客流量 不稳定、管理质量不佳等问题, 部分班线发展成熟, 部 分班线客流量较少。近年来湛江市政府积极推进公共交 通管理, 有助于完善市区交通网络, 使得交通拥堵地区 实现合理进行分流引导, 提高公交车行驶速度, 降低民 众出行时间; 有序健全指标系统, 发挥道路标识的引导 作用, 降低车辆误行、错行、绕行概率, 减少不必要的 交通拥堵, 同时扩大城市公共交通覆盖面, 实现城区、 城郊、乡镇交通顺畅衔接, 进而切实提升湛江市经济建 设引擎能级, 改善城市各项投资环境, 完善地方产业结 构, 为现代化事业发展创造条件。湛江市是区域经济建 设、资源协调的重点枢纽, 强化湛江市区公共交通管理, 不光可以为经济社会发展提供支撑, 也能够为提升公共 服务水准。使得社会民众能够安全、快速、舒适的实现 坐车、中转、联运, 因此促进公共交通事业建设, 不仅 有助于当地经济发展, 为呈现一体化进程带来推动力, 也可以积极改善民生，提升民众幸福感。

\section{3. 湛江市区公共交通管理存在的主要问题}

\section{1 存在宰客、拒载、延迟等现象}

湛江市区目前在公共交通管理过程中面临着公交 车存在宰客、拒载和延迟的现象, 如部分公交线路规范 性不足, 在收费过程中并未按照公交公司实际收费, 在 春运、节假日期间私自涨价，或私自上调首末班车定价; 部分公交车在行驶过程中对人流量较少的站点并不每 次停靠, 造成民众出行受到约束, 并有民众反映存在拒 载老年人、孕妇、病人的情况; 近年来湛江市区公交车 延迟现象也逐渐增多，一方面是由于节假日、高峰期间 人流车流量较大, 造成道路堵塞, 另一方面则是由于公 交车司机职业道德不高, 如首班车进站晚、发车晚; 起 始站发车时间到了到司机尚未上车等。在对多个公交站 点共计 100 名候车民众进行交流时发现，不少民众遭到 过宰客、拒载、延迟等现象 (如表 2 所示)。

表 2 湛江市民众乘坐公交车遭遇宰客、拒载、延迟 现象的统计

\begin{tabular}{|c|c|c|}
\hline 项目 & 人数 & 占比 \\
\hline 仅遭遇过宰 & 3 & $3 \%$ \\
\hline 仅遭遇过拒 & 12 & $12 \%$ \\
\hline 仅遭遇过延 & 13 & $13 \%$ \\
\hline 遭遇过宰客 & 7 & $7 \%$ \\
\hline 遭遇过宰客 & 12 & $12 \%$ \\
\hline 遭遇过拒载 & 31 & $31 \%$ \\
\hline 都遭遇过 & 9 & $9 \%$ \\
\hline 都没遭遇过 & 13 & $13 \%$ \\
\hline
\end{tabular}

\section{2 交通线网结构不合理}

湛江市区目前所规划的公共交通网络建设主要以 老城区为中心，同时关注新城区公共交通建设，出现区 域线路分布过密，城区、城郊和乡镇之间衔接不畅，整 体交通线网结构与城市规划并不完全匹配，当前公交线 路也缺乏统一导向, 各线路之间缺乏资源互补, 虽然公 交线路数量很多, 但在立体化空间布局中有所欠缺, 制 约公共交通线网发挥高效率作用。市区主干道在民众出 行高峰期间车流量过大, 居民区、商业区相应次干道、 支干道数量匹配明显不足, 加之道路连通性较差, 路网 需求难以满足实际需要, 造成车流分流效率不高, 干道 对接节点压力大、流通性差, 在高峰时段造成严重拥堵。 湛江市区道路主要为平面交通, 缺少必要的立体行人过 街, 行人天桥、地下通道等设施较少, 导致人流和车流 交通出现严重冲突, 由于整体构设不够科学, 未能按照 国家标准设置立体过街设施, 致使道路信号灯较多, 人 
流只能依托斑马线的方式进行过街, 造成部分区域人车 争行。除此之外少数交通线路设置和红绿灯配置不规范, 导致少量行人横穿马路, 不光干扰车辆正常行使, 也容 易出现安全隐患，引发交通拥堵。

\section{3 基础设施建设有待改进}

湛江市区火车站人员转换规模较大, 部分生产生活 集中区域、商业区人流量较大, 但不少集散点并无换乘 中转方便的大型公交枢纽, 造成人员积压现象严重, 不 少集散点公交指示信息不明，导致公共服务水平不高。 湛江市区各主要集散点之间的主要干道, 承接着当地较 多车流量, 且随着产业开发强度提升、机动车数量增多, 外来车量数量也逐年增多, 加之节假日高速免费等因素 也使得湛江市区原本趋于饱和的基建设施供需关系更 为紧张, 此外商业区周边道路停车位数量难以满足逐年 增多的机动车停放需要, 由于停车位供不应求, 导致部 分机动车出现乱停乱放现象, 造成白天在商圈、车站、 学校周边大量堵塞, 晚上在餐饮区、商业广场周边大量 堵塞。

\section{4. 湛江市区公共交通管理存在问题的成因}

\section{1 宏观管理政策效果不佳}

城市公共交通具有一定公益性特征, 湛江市区公共 交通建设存在问题的首要原因是宏观管理环境不佳。如 近年来湛江市区红绿灯中、交叉路口所出现的车流与人 流争抢、民众横穿马路等现象时有发生, 反应出主管部 门交通管理能力不足, 包括宣传教育覆盖面不广以及惩 处手段不力。湛江市区公共交通管理中存在协作机制失 灵现象, 交管部门在行权过程中存有管理缺位、管理失 位现象, 由于整体建设缺乏规范性, 未能根据时代需求 和实际需要进行建设, 致使公共交通建设发展缓慢。公 共交通有序建设离不开完善的管理体制, 目前湛江市区 公共交通整体管理存在一定问题, 如部分公共交通候车 亭、停车站、公交站台等公共基础设施并不完善, 民众 等车环境相对较差; 交通标示牌存有信息不准、指向混 乱、更新滞后等问题, 如交通标示内容不规范、交通标 志与附近工程不配套、交通网络更新速度不及时、路标 的字符图案不符合国家标准, 导致车辆行驶面临困难。

\section{2 城市建设规划不合理}

公共交通站台属于换乘枢纽, 民众在出行过程中 可通过中转的方式迅速到达目的地。但目前湛江市区城 市建设规划并不合理, 公交站场层次感不足、立体化服 务欠缺, 不少公交站场换乘能力不佳、换乘设施不足, 同时公交首末站设置并不科学，虽然城区公交车线路众 多, 但城郊、开发区公交车始末站较少。此外湛江市区
在城建规划中并未贯彻战略层面思想, 在红绿灯距离分 配和时间分配、立体过街设施完善、指示标志规范等方 面缺少管理，在局部交通规划中，人车分流道、交叉匝 道、停车位设置存在不科学现象, 造成次干道和支干道 能够为主干道所带来的压力分流较少，对公共交通服务 能力提高造成约束。

\section{3 公共交通基建设施资金不足}

湛江市区在公共交通管理建设中面临资金缺乏现 象，这也是公共交通事业发展缓慢的一大原因，尽管湛 江市政府已通过公共交通班线车辆强制险、燃油费等补 贴规定，但相比而言仍显单薄。2013 年湛江市区公交公 司推出多条微公交路线, 并将部分班线首末站逐步延伸 至乡镇, 但由于人流量较少、管理水准不高造成经营亏 损严重，由于基建设施资金不足，对政府造成较大财政 压力, 班次频率也有所减少。如始末站为湛江机场和海 田公交站的机场专线, 首班车和末班车时间分别为 7 点 和 22 点, 已难以满足民众实际出行需要; 直达湛江奥 体的公交车站主要为 48 路和 63 路, 也难以满足实际需 求。

\section{5. 湛江市区公共交通管理改进对策}

\section{1 健全管理体制}

湛江市区交通拥堵具有明显的潮汐车流现象，白天 在商圈、车站、学校周边大量堵塞, 晚上在餐饮区、商 业广场周边大量堵塞, 因此首先需要完善管理体制, 交 管部门应运用智能交通项目, 形成海量数据资源池, 提 升警力资源利用率，通过融合各项信息数据，突出当期 交通管理的重点和难点所在, 紧抓实时数据, 在大数据 资源池中进行分析, 并指导一线工作开展。其次在商圈、 车站、学校、餐饮区、商业广场附近以及公交始末站、 主要换乘站附近建立停车场, 降低由于私家车过多进入 主城区造成的拥堵。湛江市区在公共交通建设过程中, 需要进一步加强人力资源建设, 从岗位人员专业知识结 构、从业经验、岗位积极性、综合素质等进行分析, 组 建出色管理团队，为扩大科技严管夯实人才基础。最后 需要出台扶持性政策, 鼓励民众通过共享自行车、电瓶 车等方式实现低碳出行, 在积极加强共享自行车、电瓶 车宣传的同时, 增加公共租赁点, 并提高机动车和非机 动车分流管理, 从管理源头提高公共交通建设效果。

\section{2 保障交通线网结构建设资金投入}

湛江市政府部门需要对城市道路、人流量、周边环 境等作出综合规划, 形成公交车专用路设置方案, 随后 明确建设预算，通过财政补助等方式为分期建设提供资 金资源，经过阶段性建设，形成公交车专用路网络，同 
时也需要通过规范路面标志、实行交通管制等方式，为 专行公交车行使创设良好的万部环境。

交路交叉口是城市公共交通管理中的难点所在, 同 时也是常见堵塞点, 在交叉口道理管理中, 需要确保公 交先行。湛江市区可对当前道路作出改进, 扩大交叉渠 化覆盖面, 对现有车道作出改进, 同时引入排查交通技 术、动态信号监控设施等, 提升交通设备设施维护保养 能力, 为公交先行制度发挥作用夯实基础。对道路基础 较弱、通信环境不良的地区, 需提高交通基础设施规划 和力度, 对改善成本较高、财政压力较大的区域, 可通 过增设会车带、车辆避让区域等方式, 避免出现少数驾 驶员在停放车辆或行驶特殊车辆时时, 无视管理规定、 挤占道路资源的现象, 切实提升公共交通管理能力, 进 而改善道路通行状况。

从公路线路设计角度出发，投入专项资金资源，提 升候车厅、公交站台、停车站、区域调动中心布置规划 能力, 提高公交站点与轨道交通站点之间的衔接性, 同 时设计符合区域民众出行需要的班车方式, 规范班车始 发时间、车次、停靠站点等, 使得民众能够通过公交转 乘迅速达到商业区、学校、车站等, 展现出公共交通全 民性和公益性特征。如在广东海洋大学寸金学院新旧校 区之间增加直达线路，提高新旧校区交通出行便捷性。

\section{3 加强场站基建设施}

湛江市区需要进一步提高场站基建设施, 减少公共 盲区, 在管理实践中, 需要进一步减少公交盲区, 扩大 公交线路、站点覆盖面, 是对边远地区、道路网络基础 较弱区域, 由交通局统一部署, 从全局角度出发进行划 片负责, 开通具有合理性的公交线路。同时积极推动微 循环公交, 在商业区、居民区、景区之间也可以实现专 线公交, 以便于游客群体乘坐公交进行周转。

湛江市政府部门通过公开招投标的方式, 引入第三 方管理模式, 并通过出台扶持性政策、调整行政审批制 度、简化审核流程、加强资源协调等方式, 为第三方管 理机构加强公共交通建设提供帮助, 或制定合理帮扶政 策和招商引资优惠政策，提升民间资本方投资积极性。 第三方参与公共交通管理, 能够提高管理质量, 实现动 态化绩效测评, 形成公共交通考评管理制度, 根据公共 交通管理特征, 成立运营管理中心, 对车辆运营服务作 出监督管理，运营管理中心平台能够高效实现信息收集、 反馈和处理, 加强资源整合, 并以先进技术为基础, 发 挥数据库价值, 使得民众能够获得更为优质的公共交通 服务。

\section{6. 借鉴武汉市公共交通管理的经验}

武汉市近年来在公共交通管理改善过程中取得明 显成效, 湛江市可学习和借鉴武汉市成功经验提升自身 公共交通管理效果。根据 2018 年数据, 目前武汉市公 交线路共 557 条, 包括专线、普线、定制公交、微循环
公交、水上公交等多种方式，其中专线包括城区专线、 郊区专线、城际专线, 目前武汉市共有在运营轨道交通 线路 9 条 (包括阳逻线), 规划在建轨道交通线路 3 条 (包括 8 号线后期工程)。武汉市在公共交通管理过程 中, 大力推进微循环线路, 该类型公交车具有车型小、 线路短、站点少等特征, 能够有效缓解民众出行中存在 的 “门对门”坐车困难, 如在武汉大学城附近实现高校 微循环公交网络, 将各高校进行连接, 并将微循环公交 网络延伸至地铁站，在景区之间也可以实现专线公交， 以便于游客群体乘坐公交进行周转; 洪山区高校较多, 高校学生之间往来较为频繁, 可以通过公共交通的方式, 使得华师、华科、中南财经、纺大等多个学校连成一块。 湛江市区也可以扩大微循环、定向公交线路, 为民众出 行提供便利。

目前武汉市公交车大部分为单层公交, 双层公交车 较少, 武汉政府计划在未来数年内进一步提高对公共交 通的投入，使得公共交通出行比例超过六成，在形成“公 交都市” 的同时，缓解城区交通拥堵、民众出行不便、 环境污染严重等问题。武汉市天河国际机场至武昌火车 站之间可以通过轨交 2 号线换乘轨交 7 号线、轨交 2 号 线换车轨交 4 号线、轨交 2 号线换乘公交 511 路的方式 实现，也可乘坐机场巴士 1 号线直达; 天河国际机场至 汉口火车站之间可通过轨交 2 号线直达最为便捷，其余 公共交通出行方式，如由机场巴士 1 号线换乘 2 轨交 2 号线, 或由机场巴士民航小区武汉线换乘 724 路、603 路、207 路等均耗费较长时间, 且出行成本较高; 天河 国际机场至汉阳火车站之间, 主要可通过轨交 2 号线换 乘 42 路, 或轨交 2 号线换乘轨交 3 号线 (6 号线) 再换 乘轨交 4 号线的方式实现。从上述换乘情况来看, 天河 国际机场至武汉三大火车站之间主要采用轨交直达或 换乘、机场巴士直达、机场巴士与轨交换乘以及轨交换 乘的公交实现。湛江市区在湛江机场、湛江新国际机场、 火车站和湛江港等交通枢纽处采用轨交直达、巴士直达 的方式提高民众公共交通出行质量。

\section{7. 结论与展望}

自上世纪六十年代起, 西方国家学术界对公共道路 交通管理研究逐步加深, 形成较为丰富的学术经验, 逐 步改善本国交通状况, 但并未彻底根治该问题。由此可 见公共道路交通管理是国际性难题, 进入新世纪后我国 对于公共道路交通管理关注度也逐渐提升。本论文采用 文献阅读法、案例分析法进行研究, 阐述与公共交通相 关的理论基础, 以湛江市区为研究对象, 对当地公共交 通管理现状作出梳理, 表述强化城市公共交通管理的重 要性, 总结湛江市区公共交通建设中出现的问题, 包括 管理体制不健全、交通线网结构与城市规划不匹配和基 础设施建设有待改进, 并探究造成这些不足的主要缘由, 包括宏观管理政策效果不佳、城市建设规划不合理和公 共交通基建设施资金不足，进而提出具有针对性的完善 公共交通建设对策，包括全管理体制、保障交通线网结 构建设资金投入和加强场站基建设施，以期能够提升湛 
江市区公共交通管理能力。

\section{REFERENCES}

[1] Liu Ce. Countermeasure research on the management of public transport infrastructure in China. Bohai rim economic outlook, 2019, (2).

[2] Xiang Rui. Research and countermeasures on public transport planning in chongqing. Science and technology economic market, 2016, (7).

[3] Li Hongyu. Discussion on problems and countermeasures in the market-oriented reform of urban public transport in China. Finance and economics, 2015, (11).

[4] Zhao Yucheng. Countermeasures and Suggestions for the control of urban traffic congestion in Hefei. Heilongjiang traffic science and technology, 2018, (11).

[5] Song Qi. Research on problems and countermeasures in the development of public transport in Changde city. Times agricultural machinery, 2017, (4).

[6] Hu Yanmengshi. Research on the existing problems and countermeasures of public transport in Xuzhou city. China university of mining and technology, 2018.

[7] Guo Fei. Analysis of problems and countermeasures of public transport in Yuci district, Jinzhong city. Shang, 2015, (5).

[8] Zhang Shenglin. Research on the development of urban public transport -- a case study of Guilin cloud rail. Beauty and The Times, 2018, (3).

[9] Zheng Liangze. Problems and countermeasures in the development of public transport in shantou. Shantou daily, 2018, (7).

[10] Liu MengQin. A study on the solution of urban traffic congestion. Nandu university, 2018, (7).

[11] Liang Renhong. Development status, problem analysis and countermeasure research of public transport in Shangrao city. Comprehensive transport, 2018, (4). 